\title{
Monocyte response receptors in BCG driven delayed type hypersensitivity to tuberculin
}

\author{
Dominik Strapagiel, Karolina Kasztalska, Magdalena Druszczyńska, \\ Magdalena Kowalewicz-Kulbat, Adriana Vrba, Agnieszka Matusiak, \\ Magdalena Chmiela, Wiesława Rudnicka
}

Department of Immunology and Infectious Biology, University of Lodz, Poland

\begin{abstract}
Tuberculosis (TB) still remains the leading cause of mortality due to bacterial pathogen. The only currently available vaccine against TB, Bacille Calmette-Guérin (BCG) is at best credited with a 50\% overall protective efficacy. Skin testing with purified protein derivative (PPD) from Mycobacterium tuberculosis is the method of detecting BCG-induced cell mediated immunity, in vivo. In the previous study we found that approximately $60 \%$ young volunteers with no history of TB, who had been subjected to neonatal BCG vaccination and revaccination(s) at school age, developed delayed type hypersensitivity (DTH) to tuberculin. The remaining volunteers were persistently tuberculin negative. Moreover, we found a significant association between BCG driven development of DTH to PPD and the polymorphism within the CD14 C/T(-159) gene for macrophage receptor recognising mycobacterial compounds. It has suggested that the CD14 gene variants may play a role in the appearance and persistence of DTH to PPD in BCG vaccinated subjects. In order to extend our study on a possible role of CD14 in BCG driven DTH response to PPD, we measured the expression of mCD14 on macrophages, stimulated or not stimulated with mycobacterial antigens, and the serum levels of sCD14. Considering the importance of CD14 - TLR2/TLR4 interactions in macrophage signalling, we determined the polymorphism of TLR2 and TLR4 genes as well as macrophage expression of TLR2 for the volunteers with and without skin reactivity to PPD. We observed a subtle but significant decrease in CD14 density on adherent monocytes from tuberculin positive versus tuberculin negative volunteers. However, we found no difference in CD14 density on monocytes enriched in CD14+ cells using anti-CD14 mAb coupled to magnetic beads. A significant increase in CD14 density was observed on macrophages stimulated with PPD and LPS but not with live BCG bacilli. However, this increase as well as serum levels of soluble sCD14 were similar in the volunteers with and without skin reactions to PPD. Thus, our suggestion on the role of CD14 in the generation of DTH to tuberculin in BCG vaccinated subjects should be further explored. The most important CD14 co-receptors are Toll-like receptors (TLRs) which activate nuclear factors for the production of inflammatory cytokines. However, we could see no association between the polymorphisms of TLR4 (Asp299Gly and Thr399Ile) and TLR2 genes (Arg753Gln and Arg677Trp) and skin responses to PPD. Also, the TLR2 density was similar on monocytes from tuberculin negative and tuberculin positive volunteers.
\end{abstract}

Key words: CD14 - TLR2 - TLR4 - BCG vaccine - Tuberculin test

\section{Introduction}

Tuberculosis (TB) is an infectious disease of high prevalence in the world. The World Health Organization reported on estimated 8.8 million new TB cases and 1.6 million people died of TB, in 2005 [1]. To gain protection, people are vaccinated with live, attenuated M. bovis BCG (Bacille Calmette Guérin) vaccine. The

Correspondence: W. Rudnicka, Dept. of Immunology and Infectious Biology, University of Lodz; Banacha 12/16, 90-237 Lodz, Poland; tel.: (+4842) 6354472, fax: (+4842) 6355818, e-mail: rudw@biol.uni.lodz.pl estimates of the BCG-induced protection against pulmonary TB vary from 0 in South India to $80 \%$ in the United Kingdom [2,3]. Nevertheless, the neonatal BCG vaccination is associated with a significantly lower incidence of TB in children. Moreover, BCG protects against severe forms of childhood TB, especially meningeal and miliary TB. Usually, BCG vaccine induces also an acquired delayed type hypersensitivity (DTH) to mycobacterial tuberculin proteins $[4,5]$. Skin testing with purified tuberculin - PPD (purified protein derivative) is the only currently available method of detecting BCG-induced DTH, in vivo. The frequency of positive tuberculin skin tests (TST) in 
previously BCG-vaccinated individuals has varied greatly depending on the population under the study [6]. In our study, positive tuberculin tests were observed for approximately $60 \%$ young volunteers with no history of $\mathrm{TB}$, who had been subjected to neonatal BCG vaccination and revaccination(s) at school age. The remaining volunteers were persistently tuberculin negative [7]. Then, we found a significant association between the BCG driven development of DTH to tuberculin and the polymorphism within the promoter region of CD14 C/T(-159) gene [8]. The prevalence of $\mathrm{CC}$ genotype was significantly higher among tuberculin positive as compared with tuberculin negative volunteers. It has suggested that the CD14 gene variants may play a role in the appearance and persistence of DTH to PPD in the individuals subjected to $B C G$ vaccination.

CD14 is a glycoprotein with 356 amino acids encoded on chromosome 5q 23-31, which exists in human in two forms: soluble sCD14 in the serum and cerebrospinal fluid and membrane mCD14 on the surface of mature myeloid cells [9]. It has been reported recently that the $\mathrm{CD} 14 \mathrm{C} / \mathrm{T}(-159)$ polymorphism is located at a GC box near the transcription start site, which serves as a binding site for Sp1-Sp2/Sp3 transcription factors that are involved in the regulation of CD14 gene transcription [10]. As a major lipopolysaccharide (LPS) binding protein, CD14 plays a critical role in the response to LPS of Gram-negative bacteria. In addition, CD14 can bind other microbial products such as peptidoglycan, lipoteichoic acid, lipoproteins and lipoarabinomannan (LAM) derived from Mycobacterium [11,12]. CD14 has been known to be associated with Toll-like receptors (TLRs). CD14 as well as TLRs are pattern recognition receptors (PRRs) which recognize the structural compounds of bacteria at the first steps of the infection. The macrophage PRRs are innate immune sensors for conservative molecules of organisms ranging from bacteria to fungi, protozoa and viruses, and they regulate mucosal inflammation and contribute to controlling host defense against infective agents $[9,13]$. CD14 interacts with Toll-like receptors, TLR-4 and TLR-2, to transmit cell signals [11,14-17]. Several reports have described a TLR2 dependent cell activation by mycobacterial cell wall lipoglicans, especially by phosphoinosytolcapped LAM (PILAM), phosphatidyl myo-innositol mannosides (PIM) ${ }_{2}, \mathrm{PIM}_{6}$ and $19 \mathrm{kDa}$ lipoprotein. On the other hand, there are data suggesting that polymorphism in the TLR2 gene at residue Arg753Gln leads to a decreased response of macrophages to bacterial peptides, resulting in an attenuated immune response in the host [18]. These data suggest that TLR2 is crucially involved in the immune response to mycobacteria [19]. Macrophages use CD14 and TLR2 to recognize mycobacterial compounds and produce cytokines that regulate cellular antimycobacterial immune response [16].

In this paper, we extended our study on a possible role of CD14 in BCG driven DTH response to PPD. For tuberculin positive and tuberculin negative BCG vaccinated volunteers we measured the expression of mCD14 on macrophages, stimulated or not stimulated with mycobacterial antigens, and the serum levels of sCD14. Considering the importance of CD14 TLR2/TLR4 interactions in macrophage signalling, we determined the polymorphism of TLR2 and TLR4 genes as well as macrophage expression of TLR2 for the volunteers with and without skin reactivity to PPD.

\section{Materials and methods}

Study volunteers. The study was performed for 154 healthy young (18-27 years) volunteers, who had been subjected to BCG vaccination according to the state policy. All individuals had been subjected to neonatal BCG vaccination. BCG revaccinations were given to those who were tuberculin negative after Mantoux testing with PPD. In this paper all volunteers were screened for DTH to PPD. None of the volunteers had a history of TB.

Monocytes. PBML (peripheral blood mononuclear leukocytes) were isolated from heparinised blood by density gradient centrifugation on Histopaque 1077 (Sigma) [20]. The cell suspension was enriched in adherent monocytes by an incubation in plastic glass culture plate $\left(1.5 \mathrm{~h}\right.$ at $37^{\circ} \mathrm{C}$ in $\left.5 \% \mathrm{CO}_{2}\right)$, in culture medium (RPMI1640 medium, $10 \%$ heat-inactivated fetal calf serum, $2 \mathrm{mM} \mathrm{L}$-glutamine, $5 \mathrm{ug} / \mathrm{ml}$ gentamicin). Membrane CD14 density was determined on freshly isolated adherent monocytes from 29 volunteers, tuberculin negative (16) and positive (13). In some experiments, adherent monocytes $\left(1 \times 10^{6} / \mathrm{ml}\right)$ were stimulated $\left(48 \mathrm{~h}\right.$ at $37^{\circ} \mathrm{C}$ in $5 \% \mathrm{CO}_{2}$ ) with $1 \times 10^{6} / \mathrm{ml}$ live $M$. bovis $\mathrm{BCG}$ bacilli (Biomed, Lublin, Poland), $10 \mu \mathrm{g} / \mathrm{ml}$ PPD (Statens Serum Institute, Denmark), $1 \mu \mathrm{g} / \mathrm{ml}$ E. coli LPS (Sigma) or in culture medium alone, in 24 wells culture plates. Considering the heterogeneity of monocytes/ macrophage population we used more selective magnetic micro-beads (MACS--Miltenyi Biotec) method for preparation of $\mathrm{CD}_{14}{ }^{+}$monocytes. PBML were isolated from heparinised blood of 23 volunteers, tuberculin negative (12) and positive (11), by centrifugation on Ficoll-Paque ${ }^{\mathrm{TM}}$ (Amersham Bioscience) and then positively enriched in CD14 ${ }^{+}$cells using MACS technique [21]. The expression of mCD14 and TLR2 receptors on those cells was determined by immunofluorescence.

Membrane expression of mCD14 and TLR2. For direct flow cytometric analysis the monocytes/macrophages $\left(10^{5}\right.$ cells $)$ were stained with $3 \mu \mathrm{l}$ FITC labelled mouse anti-human mCD14 mAb (CD14-FITC and FITC mouse $\mathrm{IgG}_{2}$ - negative control, from Becton Dickinson) and $5 \mu \mathrm{l}$ phycoerythrin-conjugated mouse antihuman TLR2 mAb (TLR2-PE and PE labelled mouse IgG2 - negative control, from eBioscience) according to manufacturers. After two washes, the cells were analysed by flow cytometry using a FACScan (Becton Dickinson) and (FlowJo software 7.2.2, Tree Star, Inc., USA). The numbers of cell analysis counts were 10000 events per tube. The density of the receptors on monocytes was expressed as median fluorescent intensity (MFI) of sample with anti-CD14 or anti-TLR2 mAb diminished by MFI value of isotypematched negative control.

Serum sCD14. The concentration of soluble sCD14 in the serum from 55 tuberculin negative and 72 tuberculin positive individuals 
Table 1. Membrane CD14 density on native adherent monocytes from tuberculin negative and tuberculin positive volunteers.

\begin{tabular}{|l|c|c|c|c|}
\hline \multicolumn{1}{|c|}{ Volunteers } & $\begin{array}{c}\text { MlI } \\
\text { mean } \pm \text { SD }\end{array}$ & $95 \%$ CI of mean & $\begin{array}{c}\text { Mann-Whitncy } \\
\text { U value }\end{array}$ & 2-tailed $\mathrm{p}$ \\
\cline { 1 - 3 } Tubcrculin negalive $\mathrm{n}=16$ & $449.2 \pm 84.7$ & $404.1-494.4$ & 55 & $\mathrm{p}=0.0317$ \\
\hline Tuberculin positive $\mathrm{n}=13$ & $378.3 \pm 70.4$ & $335.7-420.8$ & 55 \\
\hline
\end{tabular}

Table 2. Membrane CD14 density on magnetic separated monocytes from tuberculin negative and tuberculin positive volunteers.

\begin{tabular}{|l|c|c|c|c|}
\hline \multicolumn{1}{|c|}{ Volunters } & $\begin{array}{c}\text { MFI } \\
\text { mean } \pm \text { SD }\end{array}$ & 95\% CI of mean & $\begin{array}{c}\text { Mann-Whitncy } \\
\text { U valuc }\end{array}$ & 2-lailed $\mathrm{p}$ \\
\cline { 1 - 3 } Tuberculin negative $\mathrm{n}=12$ & $6533.9 \pm 1761.4$ & $5414.7-7653$ & \multirow{2}{*}{61} & $\mathrm{p}>0.05$ \\
\hline Tubcrulin positive $\mathrm{n}=11$ & $6201.4 \pm 1090.6$ & $5468.8 \pm 6934.1$ & & \\
\hline
\end{tabular}

was assessed using an enzyme-linked immunosorbent assay (sCD14 Human Quantikine Kit (R\&D, MN, USA). The optical density (OD) of each sample was determined by using a multifunctional counter Victor 2 (Wallack Oy, Turku, Finland) set at $450 \mathrm{~nm}$.

TLR4 and TLR2 genes polymorphisms. Genomic DNA was obtained from $200 \mu \mathrm{l}$ of EDTA-anti-coagulated blood using Qiamp DNA MiniKit (Qiagen, Hilden, Germany) according to manufacturers instructions. Two known functionally important single nucleotide polymorphisms (SNPs) within TLR4 gene (Asp299Gly and Thr399Ile) were investigated by RFLP-PCR (restriction fragment length polymorphism-polymerase chain reaction). We analysed TLR4 Asp299Gly polymorphism using primers: forward 5'- GAT TAG CAT ACT TAG ACT ACT ACC TCC ATG -3' and reverse 5'- GAT CAA CTT CTG AAA AAG CAT TCC CAC -3'. DNA fragments were digested with NcoI (Fermentas). The TLR4 Thr399Ile polymorphism was analysed using primers: forward 5'GGT TGC TGT TCT CAA AGT GAT TTT GGG AGA A-3' and reverse 5'- CCT GAA GAC TGG AGA GTG AGT TAA ATG CT 3 ' and HinfI (Fermentas) [22] Genotyping for TLR2 Arg753Gln and TLR2 Arg677Trp variants was performed by RFLP-PCR. To detect the mutation at codon 753 a fragment of DNA was amplified using the primers: forward 5?-CCT ACT GGG TGG AGA ACC T3' and reverse 5'-GGC CAC TCC AGG TAG GTC TT-3' RFLP was performed using AciI restriction enzyme (Fermentas) [23].

Tuberculin Skin Test. Tuberculin RT23 (2 IU) was injected intradermally in the forearm of BCG-vaccinated volunteers. An induration of at least $10 \mathrm{~mm}$ was considered as a positive tuberculin test.

Ethical issues. The study was approved by the Human Ethics Committee.

Statistical analysis. The analyses were performed using Statistica 5.0 (Statsoft). A comparison between the various genotypes in TT + and TT- volunteers was made using the chi-square test. A comparison of mean values for $\mathrm{SCD} 14$ and median values for mCD14 and TLR2 MFI (median fluorescent intensity) was made by MannWhitney U-test. A p value 0.05 was considered significant.

\section{Results}

\section{CD14 receptors}

In healthy humans, the monocytes consist $1-5 \%$ of leukocytes. The CD14 is a specific marker of monocyte/macrophage cell population. To measure the expression of CD14 on monocytes we prepare PBML suspensions enriched in monocytes. Two methods were used for this purpose. By the adherence of PBML to plastic glass we obtained the cell suspension of adherent monocytes. On average, $79 \%$ adherent monocytes were stained for CD14 antigen. There was no significant difference in the percentage of CD14+ cells in adherent monocytes from tuberculin negative $(81 \pm 7)$ and tuberculin positive $(75 \pm 11)$ volunteers. However, CD14 density was slightly higher on native adherent monocytes from tuberculin negative (449.2 \pm 84.7$)$ than tuberculin positive $(378.3 \pm 70.4)$ volunteers. This difference was significant $(\mathrm{p}=0.0317)$ (Table 1). By magnetic positive separation with CD14 specific $\mathrm{mAb}$ we obtained more homogenous monocyte suspensions composed of $95 \pm 4 \%$ CD14+ (tuberculin positive group) and $96 \pm 4 \% \mathrm{CD} 14+$ (tuberculin negative group) monocytes. We observed no significant difference in CD14 density on magnetic separated monocytes from tuberculin negative $(6533.9 \pm$ $1761.4)$ and tuberculin positive $(6201.4 \pm 1090.6)$ volunteers (Table 2).

The significant difference in mCD14 density on native adherent monocytes from tuberculin positive and tuberculin negative BCG vaccinated volunteers prompted us to measure the expression of this receptor on the cells stimulated with mycobacterial antigens and LPS as a positive control. The adherent monocytes from volunteers responded to PPD and LPS by a significant increase in mCD14 density (Fig. 1), however, the response of the macrophages from tuberculin positive and tuberculin negative subjects was almost equally intensive (Fig. 2). On the contrary, we did not observe any effect of live BCG bacilli on the expression of mCD14 on the surface of stimulated macrophages. Then, the levels of sCD14 in the serum from 55 tuberculin negative and 72 tuberculin positive individuals were tested by ELISA. The average concentration of sCD14 in the sera from tuberculin negative and tuberculin positive volunteers was almost the 

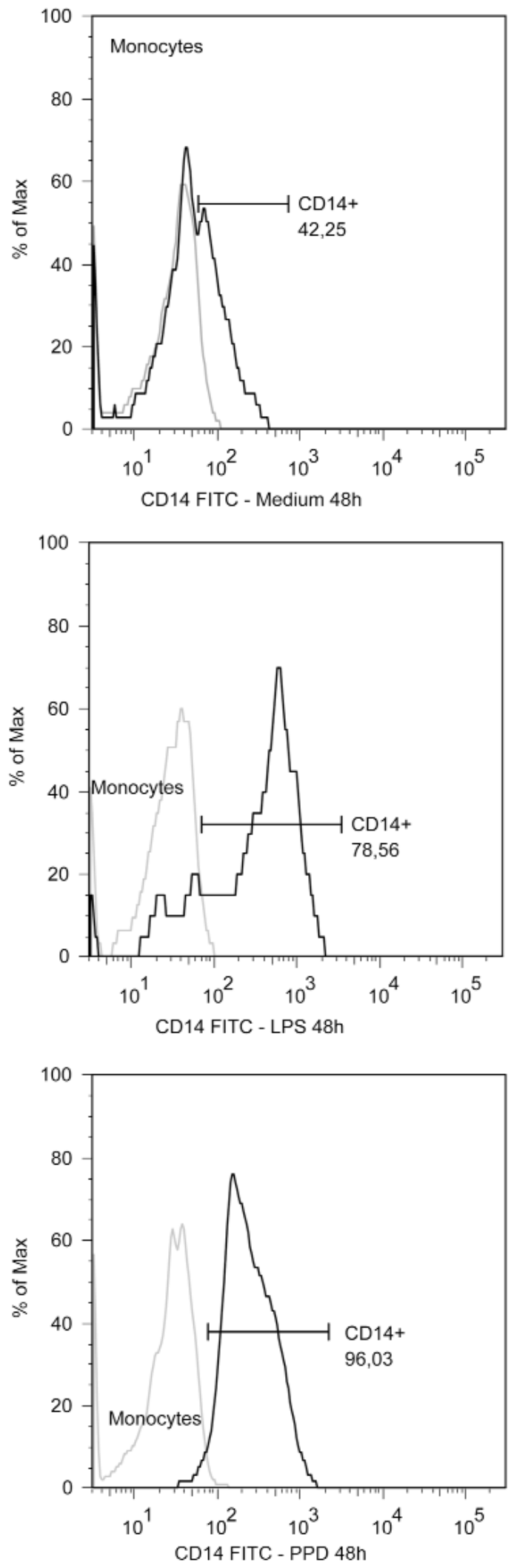

Fig. 1. Representative data on staining of adherent monocytes with $\mathrm{CD} 14-\mathrm{FITC} \mathrm{mAb}$. The monocytes were incubated for $48 \mathrm{~h}$ in medium alone (unstimulated cells) or they were stimulated with $E$. coli LPS or PPD from M. tuberculosis.

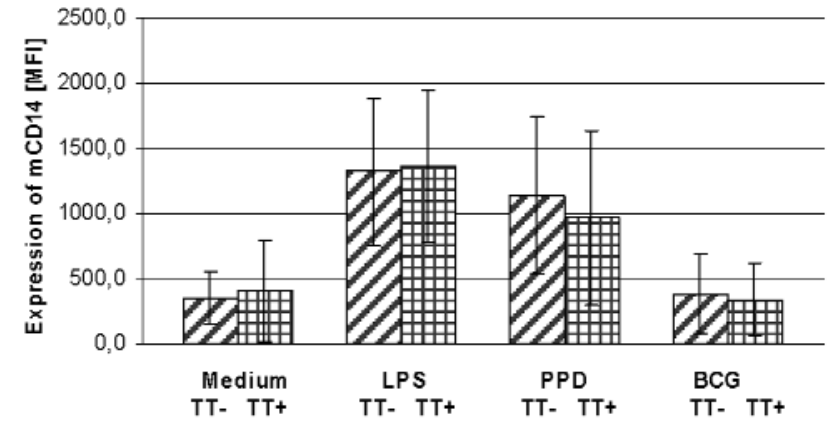

Fig. 2. The CD14 density on adherent monocytes from tuberculin negative (TT-) and tuberculin positive (TT + ) volunteers. The cells were incubated for $48 \mathrm{~h}$ in medium alone (unstimulated cells), or they were stimulated with E. coli LPS, PPD from M. tuberculosis or live $M$. bovis BCG bacilli.

same: $1461 \pm 420 \mathrm{ng} / \mathrm{ml}$ and $1475 \pm 483 \mathrm{ng} / \mathrm{ml}$, respectively. We previously reported [7] that there was no association between the serum sCD14 levels and CD14 C/T (-159) promoter polymorphism. In this paper, we could see no correlation between the serum SCD14 concentration and mCD14 density on adherent $(\mathrm{r}=0.008, \mathrm{p}=0.97)$ or magnetic separated $(\mathrm{r}=-0.06$, $\mathrm{p}=0.7865$ ) monocytes, either in tuberculin positive or tuberculin negative group.

\section{Toll-like receptors (TLRs)}

Our aim was to investigate whether the presence of TLR4 and TLR2 polymorphisms had any influence on the development of DTH to PPD in BCG vaccinated volunteers. We studied TLR4 Asp299Gly and TLR4 Thr399Ile polymorphisms for tuberculin negative (62 and 61 respectively) and tuberculin positive subjects (82 and 81 respectively) (Table 3 ). Both groups were in Hardy - Weinberg equilibrium at the polymorphic loci studied. The TLR4 Asp299Gly and TLR4 Thr399Ile polymorphisms were in linkage disequilibrium as it had been reported earlier [24]. The frequencies of mutated alleles (homozygous and heterozygous) were compared between the volunteers with and without DTH to PPD. We found no significant difference for TLR4 Asp299Gly and TLR4 Thr399Ile mutations between tuberculin negative $(13 \%)$ and tuberculin positive $(5 \%)$ subjects. Also, we investigated TLR2 Arg677Trp and TLR2 Arg753Gln for 62 tuberculin negative and 79 tuberculin positive volunteers. The TLR2 Arg667Trp polymorphism did not occur in the volunteers under the study. This is consistent with the results of the previous studies which identified no individuals carrying this polymorphism in Caucasians [23]. The distribution of the TLR2 Arg753Gln polymorphism is presented in Table 3. The study groups were in Hardy-Weinberg equilibrium. The TLR2 Arg753Gln polymorphism is rare among Poles and 
Table 3. Distribution of TLR4 and TLR2 polymorphisms among tuberculin negative and tuberculin positive volunteers

\begin{tabular}{|c|c|c|c|c|c|}
\hline Genotype & Allotype & $\begin{array}{l}\text { Tuberculin negative } \\
\text { Number }(\%)\end{array}$ & $\begin{array}{l}\text { Tuberculin positive } \\
\text { Number }(\%)\end{array}$ & $\begin{array}{c}\mathrm{X}^{2} \text { with Yales } \\
\text { correction } \\
\text { / p value }\end{array}$ & $\begin{array}{l}\text { Odds ratio } \\
(95 \% \mathrm{CI})\end{array}$ \\
\hline \multicolumn{6}{|c|}{ ILR4 Asp299Gily (n=144) } \\
\hline Asp299Asp & & $54 \quad(87 \%)$ & $78 \quad(95 \%)$ & $2.02 / \mathrm{p}>0.05$ & $0.35(0.1-1.21)$ \\
\hline Asp299Gly & & $8(13 \%)$ & $4 \quad(5 \%)$ & $2.02 / \mathrm{p}>0.05$ & $2.89(0.83-10.08)$ \\
\hline \multirow[t]{3}{*}{ Gly299Gly } & & 0 & 0 & & \\
\hline & $\Lambda s p$ & $116(94 \%)$ & $160(98 \%)$ & $1.93 / p>0.05$ & $0.36(0.11-1.23)$ \\
\hline & Gily & $8(6 \%)$ & $4(2 \%)$ & & \\
\hline \multicolumn{6}{|c|}{ ILR4 Ihr399lle $(n=142)$} \\
\hline Ihr399' lhr & & $53(87 \%)$ & $77(95 \%)$ & $2.04 / \mathrm{p}>0.05$ & $0.34(0.1-1.2)$ \\
\hline Thr3991le & & $8 \quad(13 \%)$ & $4(5 \%)$ & $2.04 / \mathrm{p}>0.05$ & $2.91(0.83-10.14)$ \\
\hline \multirow[t]{3}{*}{ Ile39911e } & & 0 & 0 & & \\
\hline & Thr & $114(93 \%)$ & $158(98 \%)$ & $1.95 / \mathrm{p}>0.05$ & $0.36(0.11-1.23)$ \\
\hline & Ile & $8(7 \%)$ & $4(2 \%)$ & & \\
\hline \multicolumn{6}{|c|}{ TI,R2 $\wedge \mathrm{rg} 753 \mathrm{Gln}(\mathrm{n}=141)$} \\
\hline$\Lambda \mathrm{rg} 753 \wedge \mathrm{rg}$ & & $60(97 \%)$ & $74(94 \%)$ & $0.20 / p>0.05$ & $2.03(0.38-10.82)$ \\
\hline$\Lambda \mathrm{rg} 753 \mathrm{Gln}$ & & $2(3 \%)$ & $5(6 \%)$ & $0.20 / p>0.05$ & $0.49(0.09-2.63)$ \\
\hline \multirow[t]{3}{*}{ Giln753Giln } & & 0 & 0 & & \\
\hline & Arg & $122(98 \%)$ & $153(97 \%)$ & $0.20 / \mathrm{p}>0.05$ & $1.99(0.38-10.45)$ \\
\hline & Giln & $2(2 \%)$ & $5(3 \%)$ & & \\
\hline
\end{tabular}

Table 4. Membrane TLR2 density on magnetic separated monocytes from tuberculin negative and tuberculin positive volunteers.

\begin{tabular}{|l|c|c|c|c|}
\hline \multicolumn{1}{|c|}{ Voluntecrs } & $\begin{array}{c}\text { MFI } \\
\text { mean }+ \text { SD }\end{array}$ & $95 \%$ Cl of mean & $\begin{array}{c}\text { Mann-Whitncy } \\
\text { U value }\end{array}$ & 2-lailed $\mathrm{p}$ \\
\hline Tuberculin negative $\mathrm{n}=12$ & $142.1 \pm 61.7$ & $102.9-181.3$ & \multirow{2}{*}{$70 \quad \mathrm{p}>0.05$} \\
\hline Tubcrculin positive $\mathrm{n}=1 \mathrm{l}$ & $168.3 \pm 152.6$ & $65.8-270.8$ & & \\
\hline
\end{tabular}

there was no significant difference in the percentage of homozygous Arg753Arg and heterozygous Arg753Gln genotypes in the group of tuberculin negative ( 97 and $3 \%$, respectively) and tuberculin positive (94 and $6 \%$, respectively) volunteers. The Gln753Gln homozygotes did not occur among the subjects included in the study. Then, the level of TLR2 was measured on the surface of magnetic separated monocytes from 23 volunteers, tuberculin negative (12) and positive (11). The average TLR2 density was similar on the cells from tuberculin negative (142.1 61.7) and tuberculin positive $168.3152 .6)$ volunteers $(\mathrm{p}>0.05)$ (Table 4$)$.

\section{Discussion}

Today, more than three billion people have been vaccinated with the attenuated $M$. bovis BCG bacilli [25].
However TB remains the leading cause of mortality due to bacterial pathogen [1]. There is a general consensus that BCG vaccine is credited with a $50 \%$ overall protective efficacy [26]. The immune responses to BCG bacilli are greatly influenced by the host cellular immune system, however, the exact role of effector mechanisms in cellular response to BCG vaccine remains to be fully established. Skin testing with PPD is the only currently available method of detecting BCG-induced cell-mediated immunity, in vivo. In our study, only about $60 \%$ of BCG vaccinated young healthy volunteers showed DTH to PPD. Recently we found that the CD14 polymorphism might play a significant role in regulating the appearance and the size of the tuberculin reaction in BCG vaccinated individuals [8]. The prevalence of CC genotype of CD14 C(159)T gene was significantly higher among tuberculin 
positive as compared with tuberculin negative subjects. CD14, a pattern recognition receptor on monocytes and macrophages, recognises bacterial structures and initiates inflammatory response $[13,16]$. In this study, we observed a subtle but significant decrease in mCD14 density on monocytes from tuberculin positive versus tuberculin negative volunteers while the cells were separated by the adherence to plastic glass. However, CD14+ monocytes obtained by positive magnetic separation from PPD responders and nonresponders showed a very similar mCD14 density. This discrepancy could be explained by a heterogeneity of monocytes/macrophages. A proportion of adherent monocytes with very low if any mCD14 expression could be present in higher numbers among monocytes from tuberculin positive than tuberculin negative volunteers. This type of monocytes could be absent from the suspensions of positively magnetic separated $\mathrm{CD} 14^{+}$cells. A lower stability of $\mathrm{mCD} 14$ on the surface of freshly separated adherent monocytes from PPD responders as compared with PPD nonresponders should not be excluded. This suggestion seems to be confirmed by a similar CD14 density on adherent monocytes from tuberculin positive and tuberculin negative volunteers, in $48 \mathrm{~h}$ cultures. An involvement of CD14 receptor in the interaction of macrophages with mycobacteria is documented by the significant increase in mCD14 density on adherent monocytes stimulated with PPD for $48 \mathrm{~h}$. But, there was no difference in the PPD driven increase in CD14 density on monocytes from tuberculin positive and tuberculin negative subjects. Also, very similar levels of soluble CD14 were detected in the sera from the subjects with and without DTH to PPD. Thus, our suggestion on the role of CD14 in the development of delayed type hypersensitivity to tuberculin in BCG vaccinated individuals should be further explored.

The most important CD14 co-receptors are TLR2 and TLR4, which activate nuclear factors and inflammatory pathway resulting in the production of cytokines important in the immune responses to mycobacteria [17,19]. Moreover, the TLR2 Arg677Trp polymorphism was found to be associated with susceptibility to tuberculosis in Tunisians [27]. However, the TLR2 Arg677Trp polymorphism previously reported among Koreans and Tunisians did not occur among Caucasian volunteers included in the study. Similarly, it was not found among Germans [23]. Another polymorphism located in the Toll IL-1R domain of human TLR2, Arg753Gln, was shown to be associated with lower IL-12 levels in lepromatous leprosy patients [28]. Thus, this polymorphism of TLR2 gene could lead to attenuated DTH development in $M$. bovis BCG vaccinated subjects because IL-12 dependent IFN- pathway is known to be crucial in cellular immunity to mycobacteria. However, we observed no significant correlation between the TLR2 Arg753Gln polymorphism, TLR2 expression on adherent monocytes, and the occurrence of DTH responses to PPD in $\mathrm{BCG}$ vaccinated volunteers.

Acknowledgements: Supported by the Ministry of Science and Higher Education grant No. 2P05A 11230 and by "GRRI-D" grant No 3/G/06 supported by EU - EFS and Polish Government.

\section{References}

[ 1] World Health Statistics. Ten statistical highlights in global public health. WHO web site. 2007. Available at: http://www.who.int/whosis/whostat2007_10highlights.pdf.

[2] Comstock GW. Field trials of tuberculosis vaccines: how could we have done them better? Control Clin Trials. 1994; 15:247-253.

[3] Franco-Paredes C, Rouphael N, del Rio C, Santos-Preciado JI. Vaccination strategies to prevent tuberculosis in the new millennium: from BCG to new vaccine candidates. Int $J$ Infect Dis. 2006;10: 93-102.

[4] Sharbaugh RJ. Administering and interpreting the PPD tuberculin skin test. 1998. Home Care Provider.1998;3:141-143.

[5] Rook GAW, Hamelmann E, Brunet LR. Mycobacteria and allergies. Immunobiology. 2007;212: 461-473.

[ 6] Roth A, Sodemann M, Jensen H. et al. Vaccination technique, PPD reaction and BCG scarring in a cohort of children born in Guinea-Bissau 2000-2002. Vaccine. 2005;23:3991-98.

[ 7] Druszczyńska M, Strapagiel D, Kwiatkowska S, Kowalewicz - Kulbat M, Różalska B, Chmiela M, Rudnicka W. Tuberculosis still posing a threat. Polymorphism of genes regulating antimycobacterial properties of macrophages. Pol J Microbiol. 2006;55:7-12.

[ 8] Rudnicka W, Strapagiel D, Druszczyńska M. et al. CD14 in Bacteria-driven chronic pathological inflammation. Helicobacter. 2006;11:353.

[ 9] Landmann R, Muller B, Zimmerli W. CD14, new aspects of ligand and signal diversity. Microb and Infect. 2000;2:295304.

[10] LeVan TD, Bloom JW., Bailey TJ, Karp CL, Halonen M, Martinez FD, Vercelli D. A common single nucleotide polymorphism in the CD14 promoter decreases the affinity of sp protein binding and enhances transcriptional activity. J Immunol. 2001;167:5838-5844.

[11] Pacheco E, Fonseca C, Montes C, Zabaleta J, Garcia LF, Arias MA. CD14 gene promoter polymorphism in different clinical forms of tuberculosis. FEMS Immunol Med Microbiol. 2004; 40: 207-13.

[12] Kim JL, Lee CJ, Jin MS, Lee CH, Paik SG, Lee H, Lee JO. Crystal structure of CD14 and its implications for lipopolysaccharide signalling. J Biol Chem. 2005;280: 1134711351.

[13] Bochud PY, Bochud M, Telenti A, Kalandra T. Innate immunogenetics: a tool for exploring new frontiers of host defence. Lancet Infect Dis. 2007; 7:531-542.

[14] Finberg RW, Kurt-Jones EA. CD14 - chaperone or matchmaker? Immunity. 2006;24:127-129.

[15] Guha M, Mackmann N. LPS induction of gene expression in human monocytes. Cell Signal. 2001;13:85-94.

[16] Underhill DM, Ozinsky A, Smith KD, Aderem A. Toll-like receptor-2 mediates mycobacteria-induced proinflammatory signalling in macrophages. PNAS. 1999;96: 14459-14463.

[17] Schroder NWJ, Morath S, Alexander C. et al. Lipoteichoic acid (LTA) of Streptococcus pneumoniae and Staphylococcus aureus activates immune cells via Toll-like receptor (TLR)-2, lipopolysaccharide-binding protein (LBP), and CD14, where- 
as TLR-4 and MD-2 are not involved. J Biol Chem. 2003;278: 5587-5594.

[18] Ogus AC, Yoldas B, Ozdemir T. et al. The Arg753Gln polymorphism of the human Toll-like receptor 2 gene in tuberculosis disease. Eur Respir J. 2004;23:219-223.

[19] Quesiniaux VJ, Delphine MN, Torres D. et al. Toll-like receptor 2 (TLR2) dependent positive and TLR2 independent negative regulation of proinflamatory cytokines by mycobacterial lipomannans. J Immunol. 2004;172:4425-4434.

[20] Chmiela M, Paziak - Domańska B, Wadstrom T. Attachment, ingestion and intracellular killing of Helicobacter pylori by human peripheral blood mononuclear leukocytes and mouse peritoneal inflammatory macrophages. FEMS Immunol Med Microbiol. 1995;10:307-316.

[21] Kowalewicz-Kulbat M, Pestel J, Biet F, Locht C, Tonnel A-B, Druszczynska M, Rudnicka W. Mycobacterium bovis BCG Mycobacteria - New Application. Pol $J$ Microbiol. 2006;55:13-17.

[22] Lorenz E, Hallman M, Marttila R, Haataja R, Schwartz DA. Association between the Asp299Gly polymorphism in the Toll-like receptor 4 and premature birth in the Finnish population. Pediatric Res. 2002;52:373-376.

[23] Schroder NWJ, Hermann C, Hamann L, Gobel UB, Hartung T, Schumann RR. High frequency of polymorphism
Arg753Gln of the Toll-like receptor 2 gene detected by a novel allele-specific PCR. J Mol Med. 2003;81:368-372.

[24] Lamb R, Zeggini E, Thompson W, Donn R. Toll-like receptor 4 gene polymorphisms and susceptibility to juvenile idiopathic arthritis. Ann Rheum Dis. 2005;64:767-769.

[25] Fine PEM. BCG: the challenge continues. Scand J Infect Dis. 2001; 33:243-245

[26] Brewer TF, Colditz GA. Relationship between Bacille Calmette-Guérin (BCG) strains and the efficacy of BCG vaccine in the prevention of tuberculosis. Clin Infect Dis. 1995;20: 126-135.

[27] Ben-Ali M, Barbouche M-R, Bousnina S, Chabbou A, Dellagi K. Toll-like receptor 2 Arg677Trp polymorphism is associated with susceptibility to tuberculosis in Tunisian patients. Clin Diag Lab Immunol. 2004;11:625-626.

[28] Kang TJ, Lee SB, Chae GT. A polymorphism in the toll-like receptor 2 is associated with IL-12 production from monocytes in lepromatous leprosy. Cytokine. 2002;20:56-62.

Submitted: 28 September, 2007 Accepted after reviews: 20 January, 2008 